\title{
Seasonal Variation in Allelopathic Activity of Japanese Red Pine Needles
}

\author{
Fukiko KIMURA and Hisashi KATO-NoGUCHI \\ Department of Applied Biological Science, Faculty of Agriculture, Kagawa University \\ Miki, Kagawa 761-0795, Japan
}

(Received May 19, 2014; Accepted August 11, 2014)

\begin{abstract}
Japanese red pine (Pinus densiflora Sieb. et Zucc.) was reported to have strong allelopathic activity. However, the allelopathic activity of the pine has not been monitored throughout a year. In this research, the seasonal change in the allelopathic activity of the extracts of Japanese red pine needles was determined. The extracts of pine needles inhibited the growth of cress (Lepidium sativum L.) and the inhibitory activity of the extracts showed the seasonal variation. The inhibitory activity of June extract was significantly greater than that of December extract. The extracts also inhibited the barnyard grass (Echinochloa crus-galli (L.) Beauv.), but the seasonal change was not apparent. The present research suggests Japanese red pine needles have allelopathic activity throughout a year and the patterns of the change in the inhibitory activity were different with cress and barnyard grass, which may be due to the different sensitivity of cress and barnyard grass to a mixture of allelopathic substances in the pine needles.
\end{abstract}

Keywords : allelopathy, growth inhibition, Japanese red pine forest, needles, variation

\section{INTRODUCTION}

Pine species grow widely in both northern and southern hemispheres and sometimes form unique forest floors. Compare to the other forests, the forest floors of pine are sparse. The growth of undergrowth plant species on the floors are restricted (Rice, 1984). One of the reasons for the sparse forest floors was considered to be due to strong allelopathy of pine species. Several putative allelopathic active substances have been reported (Chu-Chou, 1978; Harris et al., 2003; Jia et al., 2003; Nektarios et al., 2005; Caboun, 2006; Fernandez et al., 2006; 2013).

Japanese red pine (Pinus densiflora Sieb. et Zucc., Pinaceae family) is distributed in Japan, Korea and China, and most common pine species in Japan. The red pine is a typical pioneer plant and can grow in relatively nutrientpoor soils. In addition, the pine also form sparse forest floors (Rice, 1984). It has also reported that the extracts of pine needles inhibited the growth several plant species and the red pine has strong allelopathic activity (Lee and Monsi, 1963; Kil and Yim, 1983). Therefore, the allelopathy of Japanese red pine may also be one of the reason to form such forest floors. However, allelopathic activity of the needle has not been monitored throughout a year. The information is probably necessary to understand allelopathy of the red pine. In this study, allelopathic activity of Japanese red pine needles was determined throughout a year.

\section{MATERIALS AND METHODS}

\section{Plant materials}

Needles of red pine (Pinus densiflora Sieb.et Zucc.) were randomly collected from 20 trees in area of $10 \times 10$ $\mathrm{m}^{2}$, in mountainous terrain in Takamatsu, Japan every three months from June 2012 to March in 2013. Annual average temperature was $16.3^{\circ} \mathrm{C}$ in a range of $5.5^{\circ} \mathrm{C}$ (January mean temperature) to $28.1{ }^{\circ} \mathrm{C}$ (August). Annual mean rainfall was $1082.3 \mathrm{~mm}$ in a range of $37.3 \mathrm{~mm}$ (December) to 150.6 $\mathrm{mm}$ (June). The climate data of 1981 to 2010 was obtained from Takamatsu local meteorological observatory $\left(34^{\circ}\right.$ $19^{\prime} \mathrm{N}, 134^{\circ} 03^{\prime} \mathrm{E}, 8.7 \mathrm{~m}$ alt.), which is about $3.5 \mathrm{~km}$ south west of the sampling place. A dicotyledonous plant, cress (Lepidium sativum L.) was chosen as test plant for bioassay because of its known germination behaviour and sensitivity to allelochemicals. A monocotyledonous plant, barnyard grass (Echinochloa crus-galli (L.) Beauv.) was chosen as test plant for bioassay due to its weedy characteristics.

\section{Extraction}

Needles of red pine (45 g dry weight) were extracted with $300 \mathrm{~mL}$ of $80 \%(\mathrm{v} / \mathrm{v})$ of aqueous methanol for 2 days. After filtration using filter paper (No. 2; Toyo Ltd., Tokyo), the residue was extract again with $300 \mathrm{~mL}$ of cold methanol for 2 days and filtered. The two filtrates were combined and evaporated with a rotary evaporator at $40^{\circ} \mathrm{C}$.

Bioassay for seedling growth

The extracts obtained from 3, 10 or $100 \mathrm{mg}$ dry weight pine needles were dissolved in methanol, and added to a sheet of filter paper in $2.8 \mathrm{~cm}$ Petri dishes. After evaporation of methanol, the filter paper in the Petri dish was moistened with $0.6 \mathrm{~mL}$ of $0.05 \%(\mathrm{v} / \mathrm{v})$ Tween 20 . Ten seeds of

Corresponding author: Fukiko Kimura, fax: +81-87-891-3021, e-mail : pinus_densiflora_sz@yahoo.co.jp 


\section{F. KIMURA AND H. KATO-NOGUCHI}

cress or 10 germinated seeds of barnyard grass were then arranged on the filter paper in Petri dishes. Barnyard grass was germinated in dark at $25^{\circ} \mathrm{C}$ for $48 \mathrm{~h}$. The hypocotyl and root lengths of cress, and coleoptile and root lengths of barnyard grass were measured at $48 \mathrm{~h}$ after incubation in dark at $25^{\circ} \mathrm{C}$. Control seeds or seedlings were arranged on the filter paper moistened with the aqueous solution of Tween 20 without the extracts. The bioassay was repeated two times with 10 plants for each determination. Inhibitory activity (\%) was calculated by the formula: [1 - (plant length treated the extracts $) /($ control plant length $)] \times 100$. Statistical analysis was performed using SPSS version 11.5. Significant differences were examined by Tukey's HSD tests at $P<0.05$. Significant differences between control and treatments were analyzed by a Tukey's-Kramer Multiple comparison test at $P<0.05$.

\section{RESULTS AND DISCUSSION}

All extracts of the pine needle inhibited root and hypocotyl growth of cress seedlings except for the extract of December (Fig. 1). The sensitivity of cress roots and hypocotyls against the extracts was not different. However, the inhibitory activity differed with the month although the pattern of the changes was similar in the roots and hypocotyls. The inhibitory activity of March extract was significantly greater than that of December extract. The inhibitory activity of March extract at concentration of $10 \mathrm{mg}$
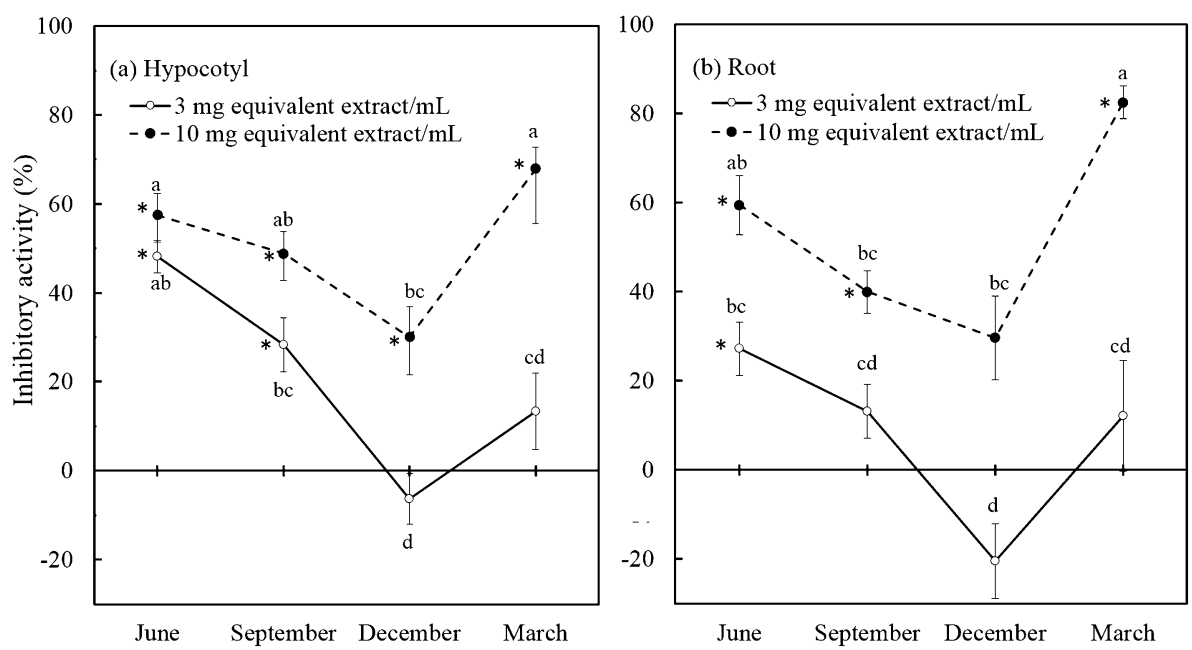

Fig. 1 Effects of aqueous methanol extracts of pine needles on (a) hypocotyl and (b) root of cress. The concentrations of tested samples were 3 and $10 \mathrm{mg}$ dry weight equivalent extracts per $\mathrm{mL}$. Hypocotyl and root length of cress was determined after $48 \mathrm{~h}$ of incubation in the dark at $25^{\circ} \mathrm{C}$. Means $\pm \mathrm{SE}$ from 2 independent experiments with 10 plants for each determination are shown. Different letters in the same panel show significant difference $(P<0.05)$ according to Tukey's HSD test. Asterisks show significant difference $(P<0.05)$ with control length and treatment length according to Tukey-Kramer Multiple comparison test.
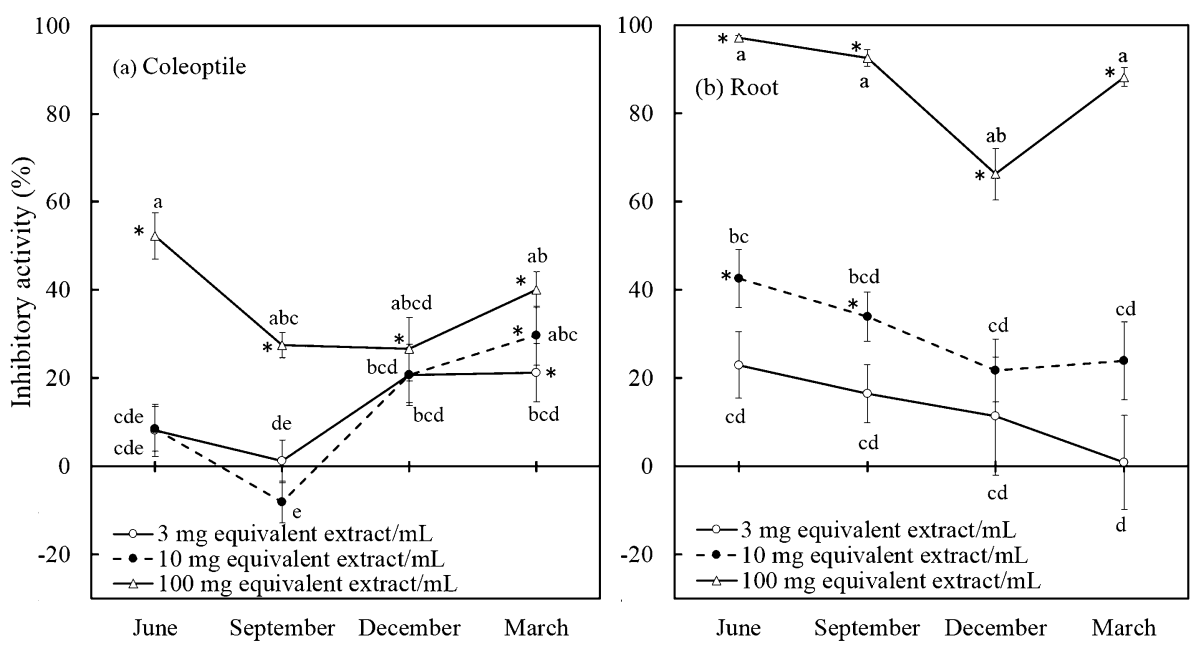

Fig. 2 Effects of aqueous methanol extracts of pine needles on (a) coleoptile and (b) root of barnyard grass. The concentrations of tested samples were 3 and $10 \mathrm{mg}$ dry weight equivalent extracts per mL. Coleoptile and root length of barnyard grass was determined after $48 \mathrm{~h}$ of incubation in the dark at $25^{\circ} \mathrm{C}$. Means $\pm \mathrm{SE}$ from 2 independent experiments with 10 plants for each determination are shown. Different letters in the same panel show significant difference $(P<0.05)$ according to Tukey's HSD test. Asterisks show significant difference $(P<0.05)$ with control length and treatment length according to Tukey-Kramer Multiple comparison test. 
dry equivalent extract per $\mathrm{mL}$ was 82.5 and $68.1 \%$ for roots and hypocotyls, respectively. Inhibitory activity of the extracts against barnyard grass was lower than cress (Fig. 2). When the concentration of the extract was increased to 100 $\mathrm{mg}$ dry equivalent extract per $\mathrm{mL}$, strong inhibition was observed on the growth of barnyard grass. However, there was no significant difference in the inhibitory activities of the extracts on the barnyard grass through a year with all concentrations.

Allelopathic activity of extracts of Japanese red pine needles had been investigated and several allelopathic active substances, such as phenolic acids, $9 \alpha, 13 \beta$ epidioxyabiet-8(14)-en-18-oic acid and abscisic acid- $\beta$-Dglucopyranosyl ester, were isolated (Lee and Monsi, 1963; Kil and Yim, 1983; Kato-Noguchi et al., 2009; 2011). 9 $\alpha$, $13 \beta$-Epidioxyabiet-8(14)-en-18-oic acid inhibited the growth cress and barnyard grass seedlings at concentrations greater than $0.1 \mathrm{mM}$. Effectiveness of the compound on cress roots and hypocotyls was 1.1- and 2.4-fold greater than that of barnyard grass roots and coleoptiles, respectively (Kato-Noguchi et al., 2009). Abscisic acid- $\beta$-Dglucopyranosyl ester inhibited the growth of cress and barnyard grass seedlings at concentrations greater than 0.1 $\mu \mathrm{M}$. The effectiveness of this compound on cress roots and hypocotyls was 4.8- and 4.5-fold greater than that of barnyard grass roots and coleoptiles, respectively (KatoNoguchi et al., 2011). It was also reported that the concentrations of some substances, such as phenolic acids, in plant leaves were high at the beginning of the growing season and decreased with the mature processes of the leaves (Cooper-Driver et al., 1977; Ohmae et al., 1996; Riipi et al., 2002). Thus, concentration and/or composition of those allelopathic substances in the extracts probably differ with the months. This may be one of the possible reasons to explain the change of the allelopathic activity of Japanese red pine needles against cress throughout a year.

On the same time, the effectiveness of those allelopathic substances may be different from the target plant species. Thus, it may be possible that there are some unknown allelopathic active substances, which varied in the concentration with month and inhibit the growth of cress but not barnyard grass. In this case, the allelopathic activity of the needles against cress would be changed significantly throughout a year, but the allelopathic activity against barnyard grass would not be changed significantly.

The present research suggests Japanese red pine needles have allelopathic activity throughout a year and the allelopathic activity showed the changes in a year. However, the patterns of the change in the inhibitory activity monitored with cress and barnyard grass were different, which may be due to the different sensitivity of cress and barnyard grass to a mixture of allelopathic substances in the pine needles.

\section{REFERENCES}

Caboun, V. 2006. Tree-tree allelopathic interactions in middle European forests. Allelopathy J. 17: 17-31.

Chu-Chou, M. 1978. Effects of root residues on growth of Pinus radiata seedlings and a mycorrhizal fungus. Ann. Appl. Biol. 90: 407-416.

Cooper-Driver, G., Finch, S., Swain, T. 1977. Seasonal variation in secondary plant compounds in relation to the palatability of Pteridium aquilinum. Biochem. Syst. Ecol. 5: 177-183.

Fernandez, C., Lelong, B., Vila, B., Mévy, J. P., Robles, C., Greff, S., Dupouyet, S., Bousquet-Mélou, A. 2006. Potential allelopathic effect of Pinus halepensis in the secondary succession: an experimental approach. Chemoecology 16: 97105.

Fernandez, C., Santonja, M., Gros, R., Monnier, Y., Chomel, M., Baldy, V., Bousquet-Mélou, A. 2013. Allelochemicals of Pinus halepensis as drivers of biodiversity in mediterranean open mosaic habitats during the colonization stage of secondary succession. J. Chem. Ecol. 39: 298-311.

Harris, M. R., Lamb, D., Erskine, P. D. 2003. An investigation into the possible inhibitory effects of white cypress pine (Callitris glaucophylla) litter on the germination and growth of associated ground cover species. Aust. J. Bot. 51: 93-102.

Jia, L., Zhai, M., Feng, C. 2003. Effects of allelopathic substances on the growth and photosynthesis of Pinus tabulaeformis seedlings. J. Beijing Forest Univ. 25: 6-10.

Kato-Noguchi, H., Fushimi, Y., Shigemori, H. 2009. An allelopathic substance in red pine needles (Pinus densiflora). J. Plant Physiol. 166: 442-446.

Kato-Noguchi, H., Fushimi, Y., Tanaka, Y., Teruya, T., Suenaga, K. 2011. Allelopathy of red pine: isolation and identification of an allelopathic substance in red pine needles. Plant Growth Regul. 65: 299-304.

Kil, B. S., Yim, Y. J. 1983. Allelopathic effects of Pinus densiflora on undergrowth of red pine forest. J. Chem. Ecol. 9: 1135-1151.

Lee, I. K., Monsi, M. 1963. Ecological studies on Pinus densiflora forest. Bot. Mag. Tokyo 76: 400-413.

Nektarios, P. A., Economou, G., Avgoulas, C. 2005. Allelopathic effects of Pinus halepensis needles on turfgrasses and biosensor plants. HortScience 40: 246-250.

Ohmae, Y., Shibata, K., Yamakura, T. 1996. Seasonal change in nagilactone contents in leaves in Podocarpus nagi forest. J. Chem. Ecol. 22: 477-489.

Rice, E. L. 1984. Allelopathy. 2nd Ed. Academic Press, Orlando, pp 424.

Riipi, M., Ossipov, V., Lempa, K., Haukioja, E., Koricheva, J., Ossipova, S., Pihlaja, K. 2002. Seasonal changes in birch leaf chemistry: are there trade-offs between leaf growth and accumulation of phenolics? Oecologia 130: 380-390. 